\title{
AN ANALYSIS OF OPERATION OF SLOVENIAN NATIONAL PUBLIC ACCESS DEFIBRILLATORS REGISTRY
}

Sara Ručigaj, Boris Podobnik, Primož Gradišek, Maja Šoštarič ${ }^{1,2}$

${ }_{1}^{1}$ Faculty of Medicine, University of Ljubljana, Ljubljana, Slovenia.

${ }^{2}$ Department of Anesthesiology and Reanimatology, Ljubljana, Slovenia.

\section{BACKGROUND AND AIM OF THE STUDY}

International resuscitation guidelines unanimously recommend formation of national registries of public access Automated External Defibrillators (AEDs). The benefits of such recommendations are two-fold: to aid both in optimising a bystander response in out-of-hospital cardiac arrest by means of either a dispatcher providing directions to the nearest AED or raising local public awareness; as well as in planning a strategic placement and further development of the AED network.

The purpose of the study was to analyse the quality of data collected and visualise the interregional differences in development of AED network, whilst identifying possible limitations in the existing methods of data collection.

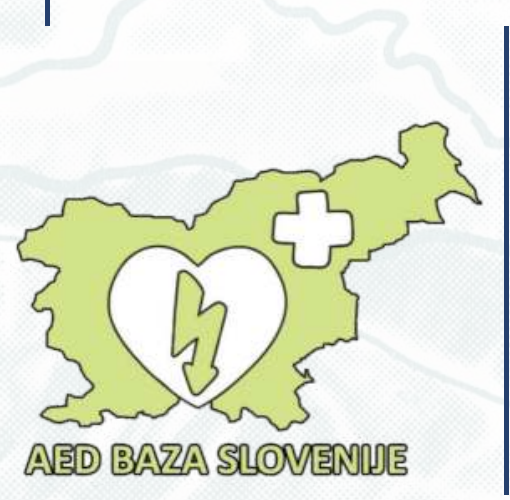

\section{ABOUT}

"AED Database of Slovenia" is an ongoing project, conducted since 2009 by students of Faculty of Medicine, University of Ljubljana, mentored by Department of Anaesthesiology and Reanimatology. Relevant data is publicly available as an interactive web map at www.aed-baza.si.

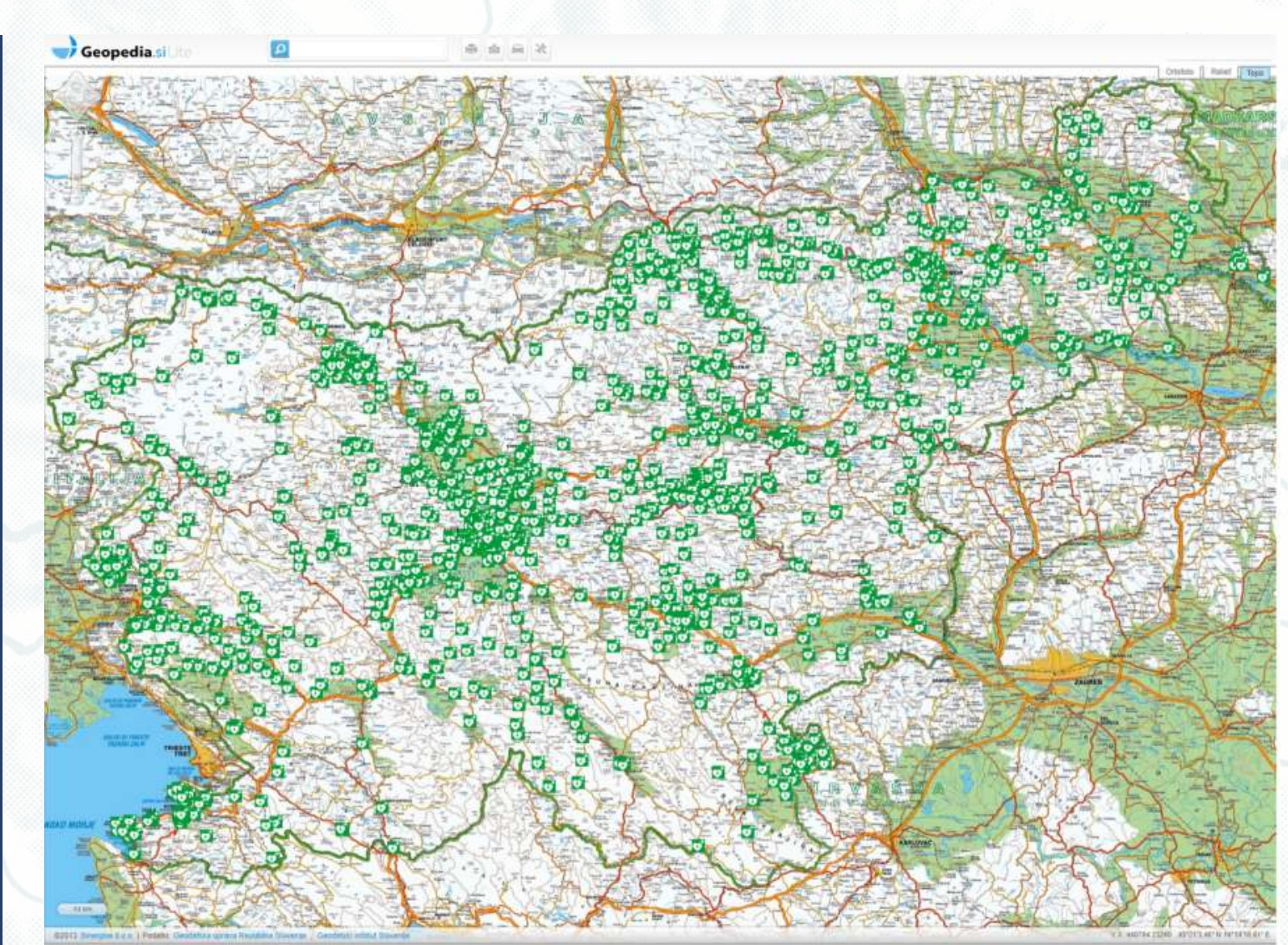

Image 1

AED database of Slovenia - Interactive public map of AED placements in Republic of Slovenia uww.aed-baza.si [Captured 5. 5. 2019]

\section{METHODS AND RESULTS}

All data collected in past 10 years up to 5. 5. 2019 was included in the study. We have analysed the range of variables that are recorded for each indexed AED, including date of entry in the registry, the institution responsible for placement and maintenance, and the exact GPS microlocation using a Geographic Information System (GIS) tool Geopedia.lite. We have cross-referenced the data with Statistical Office of Republic of Slovenia population data and the Surveying and Mapping Authority of the Republic of Slovenia.

Image 2:

per AED unit by Statistical Region of Slovenia

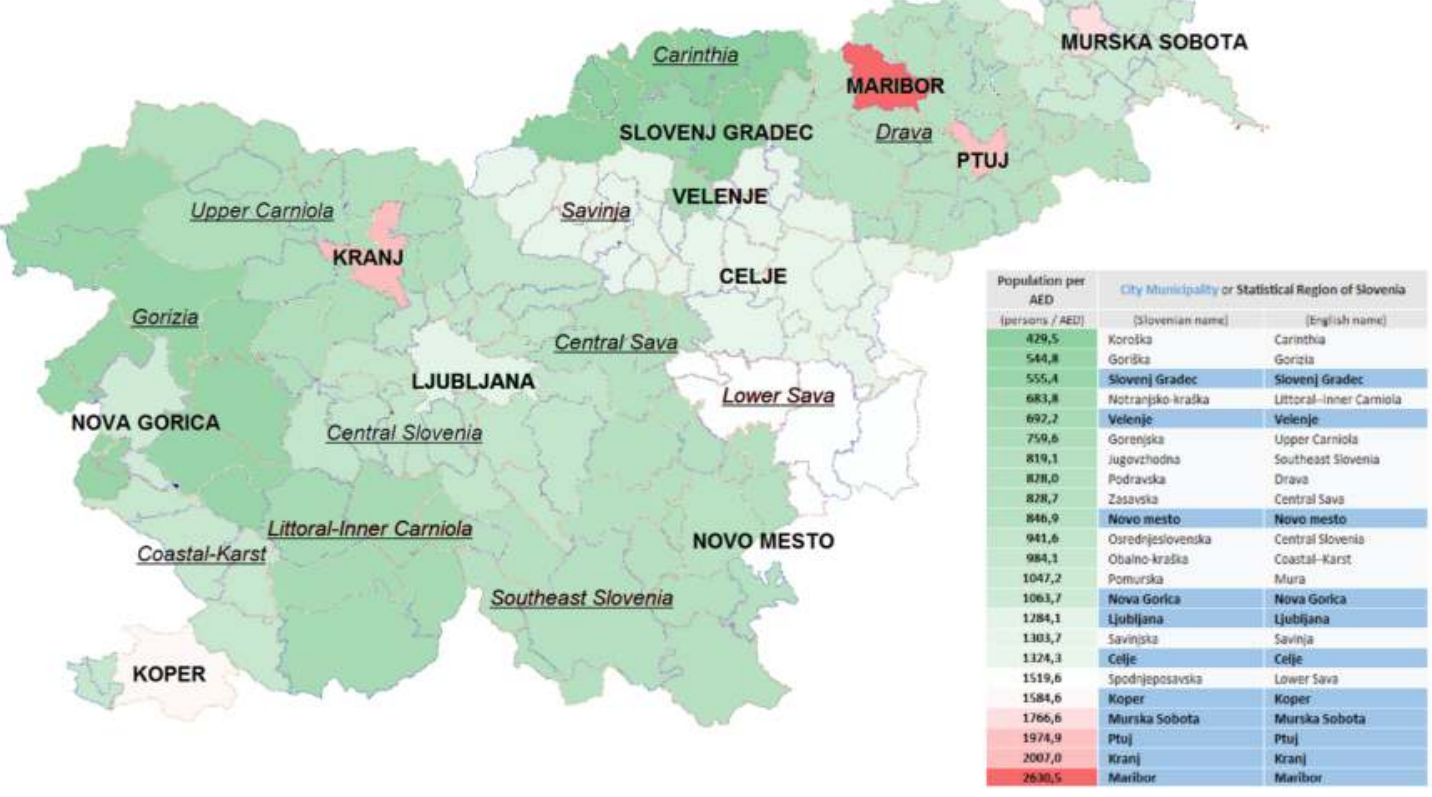

Image 3:

Average surface area per AED unit by Statistical Region of Slovenia (City Municipalities analysed and displayed separately)

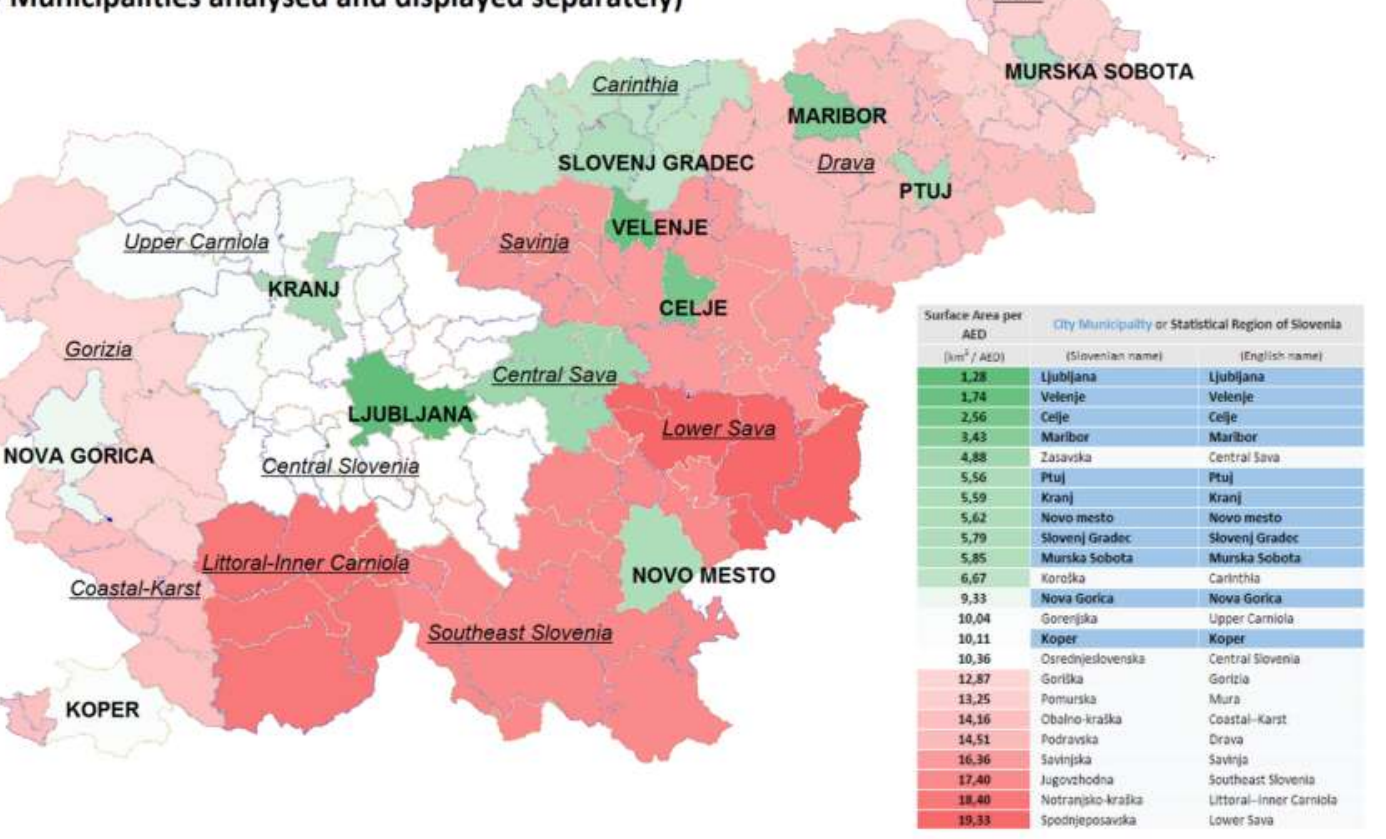

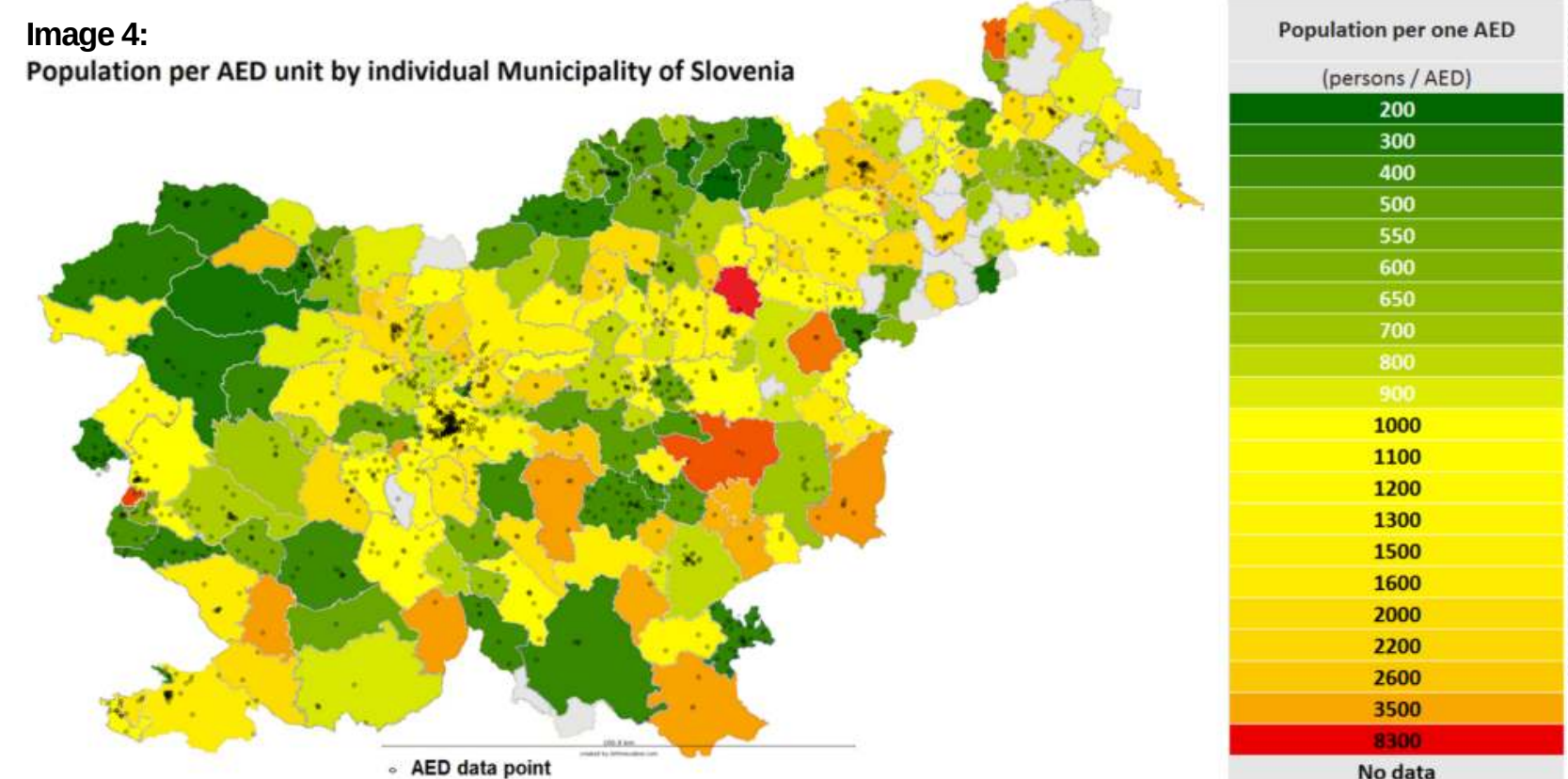

Graph 1:

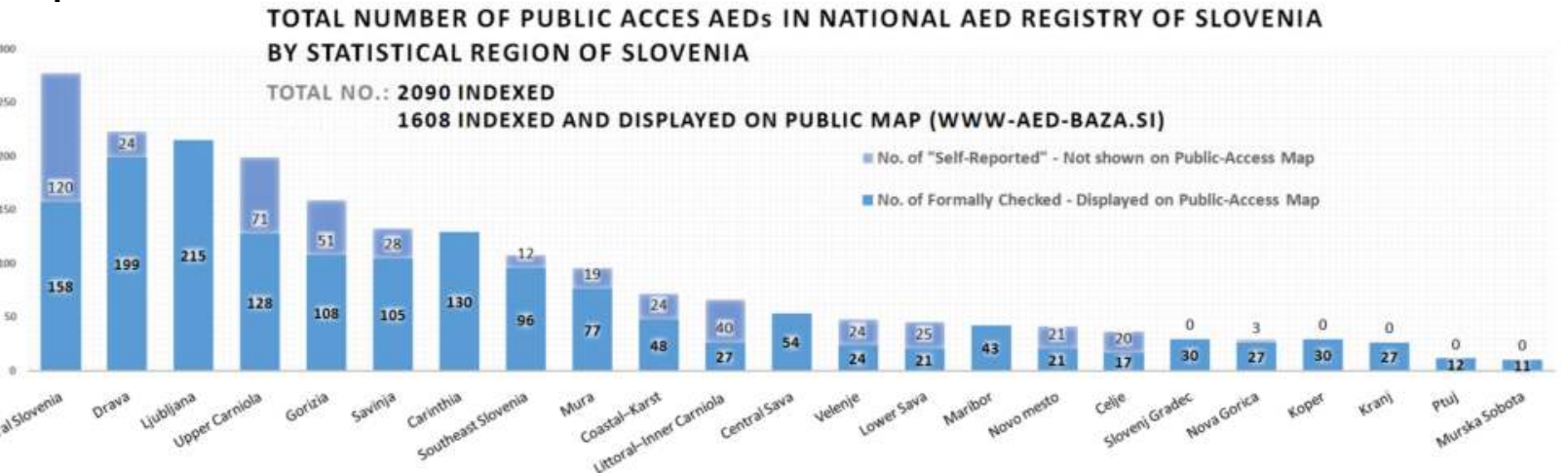

\section{CONCLUSIONS}

Even though nationwide AED coverage appears satisfactory, graphical representations of AED entries reveal a vast (exceeding factor 10) inter- and intraregional variation in density and distribution of AEDs that exceeds deviations that would be expected due to differences in demographic distribution. Methods local communities employ to maintain the AED network and promote the use of AEDs also vary significantly, so efforts to maintaini a centralised and up-to-date national registry are well-grounded. 